\title{
Is It Worth Doing Science Online? A Reflexive View on the Online Surveys
}

\author{
Andrey V. Rezaev ${ }^{1}$, Anastasia A. Ivanova ${ }^{2}$ \\ ${ }^{1}$ Faculty of Sociology, St. Petersburg State University, Russian Federation, rezaev@hotmail.com, a.rezaev@spbu.ru \\ ${ }^{2}$ Faculty of Sociology, St. Petersburg State University, Russian Federation, anaspis100@gmail.com
}

\begin{abstract}
The paper addresses the issues and challenges scientific communication is facing in current scholarly practices both within a specific scientific community and public at large. First, the paper presents methodological groundings for studying communication of results as a particular mechanism of operating with discourse. Such methodological framework focuses on the process of 'black-boxing' of scientific results. Further, the authors illustrate a way such results go from a hypothesis to a scholarly output, and call for actions. On the basis of the Online Surveys organized and conducted by the American-Russian Research Laboratory at St Petersburg State University (www.tandem.spbu.ru) for a specific field research in 2017-2018, the authors demonstrate gradual detextualization and generalization of results, which are inherent to the specific way of scientific persuasion. Finally, the authors outline the paths of the current transformation of scientific knowledge production and dissemination which calls for further research problematization.
\end{abstract}

KEYWORDS: scientific communication, black-boxing, generalization, knowledge distribution, online surveys

\section{Introduction}

Sociology of science has emphasized the importance of informal communication in the process of scientific knowledge production. Notwithstanding the significance of this discussion, this paper is oriented to discuss the issue of scientific communication in terms of the written output of scientific activities. Even being informal, scientific communication almost always entangles the substance of formal communication (Latour \& Woolgar 1986), which becomes possible primarily by virtue of visual representations. Indeed, it is the invention of new forms of inscriptions and transcriptions of knowledge that made feasible for objects to become mobile and immutable through time and space due to their representation through texts, charts, tables, etc. These new forms of representation consequently became one of the most influential causal factors of modern science success (Latour 1986). Thus, scientists "pack the world into words", converting real objects into referents of discourse (Latour 1999, 30).

One of the main distinctive features of science is its legitimate superiority over other truthclaiming practices, especially when matter comes to establishment of facts concerning reality: "in modern societies, science is near to being the source of cognitive authority: anyone who would be widely believed and trusted as an interpreter of nature needs a license from the scientific community" (Barnes and Edge 1982, 2, cited in Gieryn, 1983, 784). How come science enjoys such avowal? It is not simply unique ways of transforming objects of nature into referents of discourse, but also particular mechanism of operating with discourse itself. Scientific description and explanation have a fundamental distinctive feature - specific mechanisms of persuasion, as Latour and Woolgar (1986) argue. The reader's belief in veracity of the claimed is one of the most essential conditions for spreading faith in a fact or, put differently, in terms of actor-network theory, for successful enlarging of supporting elements in a network.

Scientific facts are constructed through coherent, often costly research activities aimed at producing traces of objects, i.e. their representations, conducting manipulations with these representations, and struggling of researchers for gradual increasing evidence of statements based on these traces (Latour\&Woolgar, 1986; Latour 1999). Thus, there is a significant consistency between a "fact" and the successful operations of various processes of 'literary inscription'. The main function of literary inscription is the effective conviction of its reader, but full conviction is possible only in case when all sources of persuasion disappear. Thus, black-boxing refers to "the way scientific and technical work is made invisible by its own success" (Latour 1999, 304). Yet specific tricks here lay not in work on the content of the text, but on operations to change the modalities of statements, i.e. efforts towards decontextualization and generalization of conditions of their production. Absence of modalities in a 
statement signals the appearance of a 'black box', and the more a statement contains the conditions for its production, the weaker are its claims that it should be automatically taken for granted. A 'counterthrust' is also possible accordingly through problematization of those processes that made possible the statement. It is possible to arrange assertions on the continuum from the fact or the strongest assertion to the statement with the least persuasive power, i.e. according to the extent to which they refer to the conditions of their construction. A 'fact' in this sense can be understood as a statement without modalities and traces of authorship (Latour, Woolgar 1986, 176). From this point of view scientific communication can be presented as a "game" wherein the main aim is to rid a statement of modalities, whereas the terms of the game assume a constant exposure to the risk of problematization of the context, potentially capable of turning an assertion from a fact into an artefact.

\section{Black-boxing of the results of one online survey}

Let us illustrate this reasoning by conducting a thought experiment based on one of the research conducted by the International Research Laboratory "TANDEM" (www.tandem.spbu.ru). Our aim here is to trace the way a scientific statement should come in order to transform from a weak assertion to a matter of fact. We have chosen certain questions of interest to us, with the help of which we can produce a certain narrative: "The data was collected via an online survey among students of higher education institutions of St. Petersburg and Moscow in the period from April to May 2017. The number of respondents was 4,276 people - students from five universities in Moscow and St. Petersburg having studied in Russian Federation for at least nine months. The data is biased towards female representatives enrolled in higher education in social sciences and humanities, as well as towards white students with a good income, and students of younger courses. The data was analyzed using the SPSS program. The simplest operations were carried out - we chose absolute frequencies as the analysis procedure for the whole array of available data.

The results show that the majority of the respondents in our sample of students evaluate their health not less than "satisfactory", basically they assess their health as "good" and "very good". Also, the results of our analysis show that the students in our sample are mostly inclined to take care of their health: $28.4 \%$ of respondents highly concern for their health, $29.3 \%$ try to take care of their health and only $8.8 \%$ and $9,4 \%$ care little or do not care at all, respectively. In addition, the majority of students (74\%) noted that they are aware of what a rational diet should be. The major part of the students, being asked the question "How often do your colleagues and friends (other students) share vegetables, fruits, and useful products with you during study hours?", answered "often" (32\%) and "from time to time" $(22.3 \%)$. As for meals during the educational process, the majority of respondents attend a cafeteria at a university: $37.3 \%$ go to the dining room constantly and $43 \%$ visit it from time to time. This research is the first attempt to investigate the mutual influence of social factors, state of health and nutritional behavior of students of higher educational institutions in Russia. Since the study was conducted among students in St. Petersburg and Moscow, and also taking into account the bias of the data, caution should be exercised in the generalization of data".

Thus, our text is full of various kinds of modalities. Although many conditions of production have already been hidden (e.g., how data was collected, by whom, why the idea of such a study was generated, etc.), the text still contains plenty of clarifications concerning both the facts themselves and the conditions of their production. Conditionally we can distinguish several contexts: (1) data collection; (2) sampling characteristics; (3) data analysis procedures; (4) specification of results; (5) limitation of the results.

Let us now simulate the situation of "migration" of statements from this text, tracing the gradual decontextualization and generalization of the results obtained. First, we need to turn into a 'black box' conditions of the production of statements. Imagine a situation wherein the conditions for the production of statements become irrelevant. For example, the results of the study become verified in subsequent TANDEM research, wherein sample of the study comprised of all Russian regions without exception. Then the specification of data collection and analysis, as well as sample characteristics, do not play any special role, we have revealed the repeatability and regularity of some connections. 
In our following narrative modalities now refer not to condition of the assertion production, but to the assertion itself: "We have analysed health and nutrition situation among Russian students and came to the conclusion that most students evaluate their health at least as satisfactorily, mostly as good and very good. Also, the results of the study show that most students take care of their health, only a small part of the students noted that they care little for it or do not care at all. In addition, most students know what should be a rational diet and tend to share vegetables, fruits and other healthy foods with each other, while during the school day most students tend to attend a cafeteria at the university". Instead of specifying both the program which researchers used and the mechanisms for working with data, we put them in a black box, replacing them with "We have analysed". We also generalized a certain sample to the "students of Russia" and now speak on behalf of a new object. We also removed references to the limitations of the study, thereby increasing the potential validity of our statements, and omitted such specifications as "within our sample", "students who answered our survey."

The next step is to create regularity, repeatability, reproducibility of the fact. Let us imagine that after publication of an article with these results several different research teams in different Russian cities will conduct similar studies. Our network is enlarging due to the insertion of the statements into various localizations, including citation. Fact-like status of assertions is now reinforced by an increasing number of operations of their production hidden from the reader's eyes, the indication of which is no longer so significant to the reader. In fact what an engaged reader sees is a number of scientific studies wherein different research teams come up with similar results. Now we need to strengthen the factuality of the assertions by complete eliminating from modalities, keeping only one, yet reinforced: instead of "Scientists analysed..." we write "Scientists prove," thereby increasing factlike status of assertions and, at the same time, affecting complete decontextualization of the previous costly and labor-intensive activities of various research teams, including the formulation of questions and their interpretation. For example, students' subjective estimations of their health will be interpreted as an objective state of health of the studied population, and rational diet will be generalized to "eat right": "Scientists prove that Russian students have good health. The majority of students care for their health and know how to eat right. During the school day, students prefer to attend cafeteria at university and share fruit, vegetables and other healthy food with each other."

\section{Instead of conclusion: Further paths for the problematization of scientific results communication}

Now we will illustrate the last step on the way of becoming a matter of fact. The communication of scientific statements is essentially connected with enlarging the network outside science. Let us imagine that our statements get into some FMCG international marketing practical training manual. These "facts" are taught in special courses in foreign universities, and for many specialists in this field become tacit knowledge. A company that produces vitamin preparations needs to expand its market segment. One solution might be to expand distribution to retail within the walls of Russian universities or nearby, or at least to expand the target audience to Russian students. What can be a fragment of an argument for this solution? "As is known, students in Russia have good health, they take care of it and eat right. Since in school hours students eat the healthy food and share it with their friends and colleagues, we believe that the university environment promotes proper nutrition". Having passed the way of gradual increasing of persuasive power by eliminating from conditions and details of various contexts, our initial statements have become unproblematic, and as a result they are used in argumentation of another statement. Thus, a new causal relationship emerges which requires verification. Thus, the statements progressively "migrated" from the field of scientific production of statements to the business environment.

Yet today scientific knowledge production directly depends on a context of its application (Gibbons et al. 1994). Unlike the traditional dissemination of scientific results through institutionalized channels, the circulation of results is often initially launched during their production. Dissemination of knowledge produced transforms from traditional communication through reporting in professional journals or participation in conferences to translations from one context of application to another. One of the consequences of such changes in the production and distribution of knowledge is the blurring of the quality criteria. In this sense, dissemination of scientific knowledge is, perhaps, 
much more flexible and at the same time more difficult to control. In conditions of enlargement of the network of dissemination channels and actors using them, shifting of contexts and conditions for knowledge application, and blurring of its quality criteria, rhetorical methods of persuasion require research (re)problematization.

\section{Acknowledgments}

Work on this paper was supported by the Grant from RSF № 18-18-00097.

\section{References}

Gibbons M., Limoges C., Nowotny H., Schwartzman S., Scott P., Trow M. 1994. The New Production of Knowledge: The Dynamics of Science and Research in Contemporary Societies. London: Sage.

Gieryn T. 1983. "Boundary-Work and the Demarcation of Science from Non-Science: Strains and Interests in Professional Ideologies of Scientists." American Sociological Review 48(6): 781-795.

Latour, B. 1986. "Visualization and cognition: drawing things together." Knowledge and Society Studies in the Sociology of Culture Past and Present, H. Kuklick (ed.). Greenwich, CT: Jai Press, 6, 1-40.

Latour B. 1999. Pandora's Hope. Cambridge, Mass.: Harvard University Press.

Latour B., and Woolgar S. 1986. Laboratory Life: The Construction of Scientific Facts. Princeton, New Jersey: Princeton University Press. 